\title{
ESCENARIOS PROSPECTIVOS DE UN NUEVO ORDEN INTERNACIONAL QUE SE VISLUMBRA LUEGO DE LA PANDEMIA COVID-19*
}

\author{
Diego Felipe Arbeláez-Campillo** \\ https://orcid.org/0000-0002-9041-9563 \\ Jorge Jesús Villasmil Espinoza*** \\ https://orcid.org/0000-0003-0791-3331
}

RECIBIDO: Abril 2020 / ACEPTADO: Mayo 2020 / PUBLICADO: Septiembre 2020

Como citar: Arbeláez-Campillo, Diego; Villasmil Espinoza, Jorge. (2020). Escenarios prospectivos de un nuevo orden internacional que se vislumbra luego de la pandemia covid-19. Telos: revista de Estudios Interdisciplinarios en Ciencias Sociales, 22 (3), Venezuela. (Pp.494-508).

DOI: www.doi.org/10.36390/telos223.02

\section{RESUMEN}

Hay buenas razones para suponer que los estragos ocasionados por la pandemia de la COVID19 en la primera mitad del 2020, erosionan de tal manera los cimientos del orden mundial imperante, estructurado desde las postrimerías de la segunda guerra mundial, que desde ya se articulan las condiciones de posibilidad para la emergencia de un nuevo o renovado orden internacional con características inciertas. En consecuencia, el objetivo de esta investigación es debatir las implicaciones políticas, económicas y socioculturales de la hipótesis del nuevo orden mundial post-coronavirus y, simultáneamente, configurar algunos escenarios posibles que bien podrían determinar el futuro próximo de las civilizaciones humanas según la lectura de Harari $(2014 ; 2015 ; 2018)$. En lo metodológico, se empleó la hermenéutica de la comprensión dialógica de Gadamer, como herramienta ventajosa cuando se trata de visualizar escenarios internacionales, junto al análisis prospectivo como pretexto para relacionar el acontecer mundial, con los textos y contextos que le dan sentido. Entre las conclusiones destaca que la crisis del orden mundial vigente es resultado de un proceso de declive histórico de los grandes modelos políticos y económicos dominantes hasta el presente y que el futuro próximo puede interpretarse mediante la visualización de tres escenarios posibles e interconectados.

Palabras clave: Escenarios prospectivos; nuevo orden internacional; pandemia COVID-19; hermenéutica de la comprensión dialógica.

\footnotetext{
* Esta contribución forma parte de las actividades de investigación y encuentro entre pares internacionales, propiciadas por el Posdoctorado en Derechos Humanos de la División de Estudios para graduados de la Facultad de Ciencias Políticas y Jurídicas, de la Universidad del Zulia.

** Grupo de investigación Lenguajes, representaciones y Educación, (Universidad de la Amazonia). Editor de la Revista Amazonia Investiga. Correo electrónico: dfaca@hotmail.com

*** Profesor titular de la Universidad del Zulia en Maracaibo, Venezuela. Coordinador del Postdoctorado en Derechos Humanos. Editor de la Revista Cuestiones Políticas. Correo electrónico: jvillasmil52@hotmail.com
} 


\section{Prospective scenarios of a new international order looming after the COVID-19 pandemic}

\section{ABSTRACT}

There are good reasons to suppose that the ravages caused by the COVID-19 pandemic in the first half of 2020, so erode the foundations of the prevailing world order, structured since the end of the Second World War, which have already been articulated the conditions of possibility for the emergence of a new or renewed international order with uncertain characteristics. Consequently, the objective of this research is to debate the political, economic and socio-cultural implications of the post-coronavirus hypothesis of the new world order and, simultaneously, to configure some possible scenarios that could well determine the near future of human civilizations according to the reading of Harari $(2014 ; 2015 ; 2018)$. Methodologically, Gadamer's hermeneutics of dialogical understanding was used as an advantageous tool when it comes to visualizing international scenarios, together with prospective analysis as a pretext to relate world events, with the texts and contexts that give it meaning. Among the conclusions, it stands out that the current world order crisis is the result of a process of historical decline of the great political and economic models that have been dominant until now and that the near future can be interpreted by visualizing three possible and interconnected scenarios.

Keywords: Prospective scenarios; new international order; COVID-19 pandemic; hermeneutics of dialogical understanding.

\section{Introducción}

La actual crisis global acontecida por la pandemia del COVID-19 trastoca de tal modo las esferas políticas, económicas y sociales de la realidad mundial que desde ya es lógico suponer la estructuración de un nuevo orden mundial post-coronavirus como una hipótesis que cobra fuerza. No obstante, desde el punto de vista científico, todavía sería demasiado pronto para determinar la finalización del orden mundial vigente (OMV) y su sustitución por un nuevo orden de cosas, en esencia y existencia diferente, en tanto espacio articulador de las relaciones internacionales en un mundo cada vez más complejo e impredecible. Por este motivo, hemos decidido considerar el nuevo orden mundial (NOM) como una hipótesis de trabajo de cara al debate, ni menos ni más.

¿Qué significa un NOM? ¿Cómo se puede determinar su advenimiento más allá de toda duda razonable? Son preguntas difíciles que por su complejidad admiten variadas repuestas provenientes de distintos lugares: científicos, políticos, ideológicos y disciplinarios, entre otros, en el marco de un debate acalorado que está en pleno desarrollo. No obstante, -a pesar de ello- en clave politológica un NOM seria en principio un fenómeno suscitado en el nivel macro-político a escala global a desarrollarse al menos en tres etapas o momento diferenciales: a) transición, b) estructuración y, c) desarrollo y consolidación. 
Escenarios prospectivos de un nuevo orden internacional que se vislumbra luego de la pandemia covid-19

Al decir de Martz Fernández (2017), las transiciones políticas por regla general se identifican por la pérdida de la hegemonía de un actor de $\operatorname{poder}^{1} \mathrm{o}$, de un conjunto de actores de poder entrelazados, mediante un dialéctico proceso que determina el surgimiento paulatino de nuevos actores y factores ${ }^{2}$ con relevancia internacional, con otras ideologías, intereses estratégicos y concepciones de la vida en sociedad y, consecuentemente, del sistema mundial. De modo que, agregamos nosotros, la transición política a un NOM, podría ser un proceso lento que implica -sin lugar a dudas- el trastocamiento de los principales modelos multidimensionales, hasta ahora imperantes como: la democracia liberal de occidente; las economías de mercado; las sociedades interculturales de base patriarcal o matriarcal fundadas en la autonomía de la persona humana y el individualismo y; en lo legal: con el declive del estado de derecho y la dignidad humana al calor de la impronta de regímenes autoritarios híbridos, como el modelo chino, que combinó en igualdad de condiciones la economía de mercado con prácticas totalitarias del comunismo para el control social, formal e informal de sus pueblos.

En este contexto, es muy usual leer en medios de amplia difusión que, por su dramático impacto, la pandemia COVID-19 significa un punto de inflexión en el estilo de vida propio de las sociedades abiertas, razón por la cual se afirma taxativamente:

Para detener la pandemia de coronavirus (COVID-19) debemos cambiar drásticamente nuestra forma de hacer casi todo lo que hacemos: cómo trabajamos, hacemos deporte, salimos, compramos, controlamos nuestra salud, educamos a nuestros hijos y cuidamos a los miembros de la familia.

Todos queremos volver a la normalidad cuanto antes. Pero parece que la mayoría de nosotros todavía no somos conscientes de que nada volverá a la normalidad después de unas semanas, ni siquiera de unos meses. Algunas cosas nunca volverán a ser como antes (Lichfield, 2020, s/p) (resaltado añadido).

Conviene reiterar que para el momento que se escribe este trabajo aún no se ha superado la pandemia por completo y tampoco se conocen todos sus efectos colaterales en la vida de las personas que padecieron la enfermedad ni, mucho menos, en el orden social en su conjunto de los países más afectados por el virus que, de hecho, podría mutar en un lapso perentorio de tiempo y convertirse rápidamente en una enfermedad más letal (Arbeláez-Campillo et al, 2019).

\footnotetext{
${ }^{1}$ Esta afirmación puede conectarse sin forzar las fuentes con lo planteado (Toro Hardy, 2007), para quien EUA viene atravesando por un proceso de declive objetivo que amenaza su rol de potencia hegemónica unipolar, apuntalado desde el final de la guerra fría, dejando en consecuencia, las puertas abiertas para el reposicionamiento de potencias emergentes como China que, de acentuarse más este proceso de perdida de liderazgo en el mundo de hoy de occidente y la potencia del norte en particular, pudiera relegarla en pocas décadas en lo diplomático, económico y militar, tal como sucedió a finales del siglo XIX y principios del siglo XX con la subordinación de Inglaterra por parte de los Estados Unidos de América.

${ }^{2}$ Cuando hablamos de actores o sujetos de poder no solo nos referimos a los Estados nacionales, además pensamos en la banca internacional, las grandes corporaciones, los liderazgos políticos, científicos y religiosos, las organizaciones criminales con impacto internacional y en todos los poderes fácticos que actúan de forma abierta a tras las sombras con una influencia considerable, aunque no puedan ser fácilmente identificados por las investigaciones sociales convencionales. Por su parte, cuando se habla de factores de poder se quiere significar a las circunstancias y escenarios que condicionan el ser y el hacer de los actores de formas multivariadas, por lo cual, se da una relación simbiótica en los actores y sus factores, tanto el objetivo como en lo subjetivo, en lo abstracto y en lo concreto.
} 
De cualquier modo, como un intento de dar respuesta provisional a la segunda interrogante formulada ¿Cómo se puede determinar el advenimiento de un nuevo orden mundial más allá de toda duda razonable? Se plantea precisamente el objetivo de la investigación, consistente en: debatir las implicaciones políticas, económicas y socioculturales de la hipótesis del nuevo orden mundial post-coronavirus y, simultáneamente, configurar algunos escenarios posibles que bien podrían determinar el futuro próximo de las civilizaciones humanas.

Mucho más pertinente cuando en un contexto de considerable incertidumbre ante el devenir, se justifica la necesidad de desarrollar análisis prospectivos, con base a evidencia empírica concreta, que configuren los escenarios posibles para alertar la labor de los hacedores de políticas y la sociedad civil organizada, sobre las realidades que se esperan, sin apuntalar, por ello, falsas expectativas en las posibilidades heurísticas y predictivas de un estudio con este designio que, muy seguramente, será superado en buena medida por los acontecimiento venideros en el corto y mediano plazo, porque la realidad en su complejidad intrínseca puede rebasar todas las visiones de futuro ${ }^{3}$ que se formular en un momento determinado.

Por lo demás, este trabajo esta divido en cinco apartados que en su conjunto intentan resolver satisfactoriamente el objetivo de la investigación. En la primera sección se da cuenta de las principales influencias que directa o indirectamente condicionaron nuestra visión particular del tema y sirvieron de base para la puesta en marcha del aparato teórico y crítico. En la segunda, se explica el andamiaje metodológico. Por su parte, en la tercera sección, se intenta argumentar las implicaciones de la hipótesis que postula el ocaso del orden mundial actual, para seguidamente, en el cuarto apartado, mostrar distintos escenarios internacionales que podrían materializarse o no, superada la crisis de la pandemia. Por último, se arriban a las conclusiones del caso.

\section{Literatura revisada}

La lectura minuciosa de distintos aportes historiográficos y filosóficos (Harari, 2014; 2015; 2018) condicionar nuestra visión del tema y simultáneamente permitieron delimitarlo en función de lo que se espera será la nueva humanidad en las próximas décadas. El propósito de este apartado es, por lo tanto, dar cuenta de las principales influencias que funcionaron como faro epistémico para el desarrollo de nuestros argumentos en torno a los constructos de NOM y sus escenarios prospectivos. Como se puede constatar en la bibliografía, esencialmente la investigación recopiló tres modalidades de fuentes documentales, a saber: a) libros neoclásicos, b) prensa internacional y, c) artículos científicos.

En anteriores publicaciones (Arbeláez-Campillo et al, 2019), se ha definido el orden mundial o internacional, desde las coordenadas del enfoque neorrealista, como un espacio sistémico determinado por la correlación de distintos intereses: políticos, estratégicos, económicos, diplomáticos y militares, entre otros, en el confluyen las distintas naciones con roles periféricos

\footnotetext{
${ }^{3} \mathrm{~A}$ pesar de sus limitaciones los intentos por diseñar escenarios que den cuenta de lo que vendrá en el futuro siempre han sido una preocupación primordial de la filosofía y de las ciencias sociales. En este orden de ideas, (Ritzer, 2005) efectúa una relectura de la obra clásica del marxismo y postula que, los pensadores dialécticos siempre se preocupan por la dirección futura que tomara las sociedades en las que están inmersos: "Este interés por el futuro constituye una de las principales razones de que la sociología dialéctica sea intrínsecamente política, pues posee una imagen del mundo futuro y su interés es promover actividades prácticas que den vida a ese mundo. En el intento de captar la naturaleza de ese mundo futuro... creen que el estudio cuidadoso del mundo contemporáneo proporciona enseñanzas valiosas. En su opinión, el cambio social es una posibilidad futura de lo que existe en potencia: las fuentes del futuro existen en el presente" (Ritzer, 2005, p.191).
} 
Escenarios prospectivos de un nuevo orden internacional que se vislumbra luego de la pandemia covid-19

o protagónicos, según el caso, y en el que se gestan conflictos, alianzas y bloques regionales de poder al estilo de la Unión Europa, junto a organismos multilaterales como la Organización de Naciones Unidas, con el propósito de gestionar las diferenciar y apuntalar objetivos comunes para el bienestar de los pueblos.

No obstante, el escenario internacional es por su propia naturaleza conflictiva hasta cierto punto caótico, por lo cual se supone que: "Los estados más fuertes o hegemónicos imponen su voluntad a los menos fuertes como condición de posibilidad para garantizar su propia supervivencia y seguridad y alcanzar sus particulares objetivos nacionales" (Arbeláez-Campillo et al, 2019, p. 138). Desde una perspectiva simplificadora, las distintas conflagraciones sucedidas desde la guerra fría hasta el momento actual podrían explicarse grosso modo como resultado una estrategia de los estados ya actores marginados: "Para minimizar la influencia de los estados poderosos en algunas regiones del mundo y revitalizar ciertas cuotas de soberanía en naciones emergentes" (Arbeláez-Campillo et al, 2019, p. 138).

A pesar de las relaciones asimétricas de poder que se desarrollaron en el mundo bipolar de la guerra fría dominado por la (URSS y los EUA), esquema que terminaría con el colapso del bloque soviético en la última década del siglo XX y con la proclamación de la democracia liberal, los derechos humanos y las economías de mercados como fase definitiva del desarrollo humano, al menos según (Fukuyama, 2015), los conflictos o catástrofes internacionales siempre han dado paso a ciertos consensos que permiten niveles suficientes de cooperación e intercambios de todo tipo, mucho más en un mundo cada vez más globalizado e interconectado como lo es el siglo XXI. En el presente, todas las naciones del mundo se ven amenazadas por el avance de una pandemia (COVID-19), con un potencial temible para destruir vidas, detener los procesos económicos y colapsar los servicios sanitarios, evidenciando que más allá de sus avances y capacidades las civilizaciones humanas siguen siendo frágiles.

Ante estas realidades, especialmente sugestivo resulto la lectura del trabajo de Calvano Cabezas (2019), que reposiciona la filosofía contractualista como una herramienta dialógica profundamente democrática, que no se limita a los dominios del constitucionalismo histórico, cuando se trata de diseñar un ecosistema sociopolítico y económico sostenible para las mayorías y, por antonomasia, una arquitectura internacional al servicio de la dignificación de la vida. Además, pone de relieve las bases éticas, epistemológicas, ideológicas y culturales que sirven de sustento al nuevo contrato social que propone como alternativa al OMV.

En este hilo conductor, se infiere que en condiciones ideales un nuevo orden internacional no debe ser el resultado de coyunturas inesperadas como guerras, catástrofes o pandemias; ni de poderes hegemónicos al servicio de elites corporativas o partidarias que imponen a las masas sus concepciones de la vida y la historia sin la construcción de un consenso previo que les de legitimidad. Un asunto trascendental para la vida de todos debe implicar, como condición sine quo non, la puesta en marcha de espacios inclusivos y deliberativos entre naciones en teoría soberanas e iguales, en derechos y responsabilidades, con el fin de armonizar sus intereses materiales y culturales y de conferir forma y contenido al NOM que se quiere alcanzar (Villasmil y Chirinos, 2016). Lamentablemente, siendo realistas todo indica que la historia no funciona de esta manera y este momento no parece ser la excepción. 


\section{Aclaratoria metodológica}

Todo texto tiene su contexto y viceversa, de ahí que la hermenéutica es la mejor alternativa metodológica cuando la acción interpretativa se despliega para comprender los distintos símbolos y signos que hablan del sentido particular de un tiempo y espacio determinado y de sus acontecimientos trascendentales, bajo el supuesto de que la realidad misma se expresa como un hipertexto que admite infinitas lecturas y diálogos intertextuales, sin que por ello se pueda llegar a revelar verdades absolutas y definitivas como proclaman ciertos historicismos de raigambre totalitaria (Popper, 1945).

Para el logro de los propósitos de esta investigación se adoptó la hermenéutica de la comprensión dialógica de (Gadamer, 1993), para la cual interpretación y comprensión de textos y contextos significan las dos caras de una misma moneda: "Sin embargo, la comprensión sólo se convierte en una tarea necesitada de dirección metodológica a partir del momento en que surge la conciencia histórica, que implica una distancia fundamental del presente..." (Gadamer, 1993, p. 4).

Pero no solo la conciencia del presente, en este caso como realidad de un orden internacional erosionado impuso la operacionalización metodológica del trabajo interpretativo, como un fluyo continuo de preguntas y respuestas (circulo hermenéutico) que bien pudiera rememorar de cierto modo a la mayéutica socrática; sino fundamentalmente, como un diálogo tridimensional en el que pasado, presente y futuro convergen en el intelecto del equipo de investigación que se atreve a hacer proyecciones, no solo como mera especulación, sino además, como visiones de futuros posibles a partir de lo que simbolizan las presentes realidades gestadas dialécticamente en un movimiento de espiral ascendente, como es el movimiento histórico de las sociedades humanas en su conjunto.

En lo concreto, la investigación que aquí se presenta no pretende negar a priori su cercanía como la modalidad discursiva del ensayo filosófico porque se desarrolló en los límites disciplinarios de las ciencias humanas y la filosofía política, desde una concepción científica post-positivista que apuesta por la interdisciplinariedad desde un: "(...) decisivo proceso de radicalización y universalización del comprender en el ámbito epistemológico y ontológico, así como del interpretar en los campos filosófico e histórico, reposicionando la categoría de sentido como eje especular" (Vergara Henríquez, 2011, p. 74).

En otro orden de ideas, desde las coordenadas de la metodología tradicional positivista, el estudio se desenvuelve mediante un diseño documental de investigación basado en la recuperación, organización, interpretación y contraste de fuentes documentales escritas, seleccionadas intencionalmente en conocimiento de su sentido y contenido.

\section{¿Ocaso del orden mundial imperante?}

En principio es más adecuado afirmar que el orden mundial imperante hasta el presente histórico no es solamente la consecuencia de la reorganización mundial acontecida acabada la segunda guerra mundial en 1945, en las conferencias de Yalta y de Potsdam, donde las potencias victoriosas del conflicto (EUA, Gran Bretaña y URSS) definieron, al calor de la dicotomía socialismo/capitalismo, sus áreas de influencia geopolítica y los contornos del NOM; sino además, como otra fase superior del proyecto político de la modernidad iniciado en occidente desde la revolución industrial en el siglo XVIII. 
Escenarios prospectivos de un nuevo orden internacional que se vislumbra luego de la pandemia covid-19

En términos materiales, Kasper (2015), indica que en la segunda mitad del siglo XX la humanidad en general a experimentado un intenso proceso de crecimiento económico que ha tenido amplias y variadas repercusiones en el OMV:

Durante las últimas dos generaciones, la mayor parte de las naciones del mundo han alcanzado un sorprendente ritmo de crecimiento económico. El estándar de vida promedio de la humanidad se ha más que duplicado desde el final de la Segunda Guerra Mundial. Para ser más preciso, el volumen de los bienes y servicios por cada habitante del mundo ha subido por no menos de $2.1 \%$ p.a. desde 1945 . Adicionalmente, el número de personas en el mundo se ha multiplicado más de 2.5 veces y ya ha sobrepasado los 7 mil millones y medio. Esto quiere decir que la humanidad está ahora produciendo unas cinco veces más de lo que producía cuando finalizó la Segunda Guerra Mundial. En el proceso, miles de millones de personas han salido de condiciones de extrema pobreza, y millones que antes se hubieran muerto jóvenes, ahora sobreviven (Kasper, 2015, p. 11).

En esta disposición de ideas, el orden mundial que se estructura y desarrolla en la segunda mitad del siglo XX se caracterizó a la sazón por articular distintos modelos como la democracia y el estado de derecho, las economías de mercado y, en lo axiológico, la Declaración Universal de los Derechos Humanos de 1948, que proclama desde su preámbulo la necesidad de producir y reproducir una realidad internacional en la cual prevalezcan valores universales como la libertad, la justicia y la paz como base para reconocer la dignidad intrínseca de toda la familia humana y los derechos iguales e inalienables de todas las personas, sin ninguna distinción (Naciones Unidas, 1948).

Por su parte, el bloque socialista trazó una particular hoja ruta para alcanzar los trascendentales objetivos de la referida declaración, no ya desde una postura liberal, sino desde un planteamiento abiertamente socialista-marxista que apostó por la planificación central de la economía, por la vía revolucionaria cómo contrapuesta a la reformista y también por la promoción de los derechos colectivos de los pueblos, como única vía posible para superar las paradojas de las "democracia burguesas del occidente hegemónico" y lograr el desarrollo pleno de la condición humana y la autodeterminación de los pueblos oprimidos, con un resultado negativo ampliamente conocido que no viene al caso detallar.

De cualquier manera, ambas tesis en disputa (capitalista y socialista) coincidían en una perspectiva materialista del desarrollo económico, basado en la necesidad de modernizar continuamente las fuerzas productivas y la sociedad mediante procesos de industrialización y urbanización, modelados por los avances científicos y tecnológicos. Ambas tesis fracasaron a su manera en aspectos cruciales para la protección de la civilización humana.

En este sentido Parra (2020), en su perspectiva del mundo que se avecina sostiene que un NOM debe gestionar como condición de posibilidad para la sostenibilidad del planeta, al menos dos aspectos cruciales que nos fueron debidamente atendidos por el OMV. Por una parte, se debe desconcentrar la acumulación de riquezas en el $1 \%$ de la población que además a instrumentalizado los recursos naturales no renovables en su afán desmedido de lucro. Por la otra, los modeles productivos más allá de sus peculiaridades ideológicas deben subordinar la búsqueda del crecimiento económico a la permanencia de la vida en el planeta para lo cual urge asimismo el desarrollo de tecnologías limpias y la superación definitiva de los combustibles fósiles como forma predominante de energía. 
En el siglo XXI se agudizan las contradicciones del orden internacional vigente, en la misma medida que sus principales modelos políticos y económicos en sus distintas expresiones, combinaciones y modalidades se tornan incapaces -de una forma u otra- de aportar soluciones definitivas a los grandes problemas de la humanidad, tales como: el calentamiento global, las violaciones sistemáticas de los derechos humanos por estado autoritarios, el terrorismo, el narcotráfico, él desempleo y la violencia de género, entre otros, con especial énfasis en las precarias realidades de los país más pobres, definidos eufemísticamente como países en vías de desarrollo, en los cuales al decir de (Morales et al, 2019), la modernidad en su sentido integral se ha experimentado de forma selectiva para beneficio exclusivo de grupos privilegiados, quedando gruesas capaz de la población, aun hoy en pleno siglo XXI, relegadas a la pobreza extrema, a la explotación y marginación como lo evidencia el caso latinoamericano de modernidad selectiva y parcial.

Las problemáticas descritas y muchas otras han debilitado, en lo material y simbólico, las instituciones, prácticas y discursos que sirven de cemento al orden globalizante deteriorando su legitimidad, sin embargo, hasta la propagación de la pandemia del COVID-19 en 2020 casi nadie se había atrevido a pregonar seriamente el ocaso del orden mundial imperante a pesar de la crisis económica mundial de 2008 que puso en evidencia los límites del crecimiento económico, lo que lleva a debatir esta hipótesis y, al mismo tiempo, a revisar que implicaciones tendría para todos el inicio de una transición a otro orden diferente con el reposicionamiento de las naciones centrales y periféricas en el entramado internacional, pero ¿ realmente estamos en ante el ocaso del orden mundial imperante? De ser afirmativa la respuesta retomados la pregunta formulada en la introducción ¿Cómo se puede determinar el advenimiento de un nuevo orden mundial más allá de toda duda razonable?

De ser cierta la opinión general que socializan los mass medios de mayor divulgación (Lissardy, 2020; Barría, 2020; The New York Time, 2020) los estragos del coronavirus significan un punto de inflexión en el orden mundial porque sus consecuencias son tan profundas y dramáticas que impulsaran una recesión económica global, crecientes tensiones políticas y conflictos armados que, en suma, acarrearan transformaciones indetenibles que rebasan por mucho las capacidades de los estados nacionales y sus respectivas formas de gobierno convenidas hasta el presente $y$; en consecuencia, deconstruyen los paradigmas que hacen posible sus interrelaciones como un todo.

Desde esta hipótesis, se deduce que la humanidad en su conjunto atraviesa sin saberlo, por una crisis histórica ${ }^{4}$ que apunta a estructurar un nuevo o renovado status quo hasta ahora incierto en su contenido, procedimientos y arquitectura, de modo que conviene representar los escenarios prospectivos de un nuevo orden internacional que se vislumbra luego de la pandemia COVID-19.

\footnotetext{
${ }^{4} \mathrm{Al}$ decir de (Caballero, 2007), en sintonía con lo postulado por el filósofo decimonónico Carl Jacob Christoph Burckhardt, la crisis histórica es una categoría de análisis que se identifica por la interacción de 5 condiciones o prerrequisitos básico: a) Se trata de un momento crucial; b) se pasa de una situación de "normalidad" a una de anormalidad; c) genera cambios irreversibles; d) toda crisis surge en una temporalidad definida que permite ubicar su proceso de gestación en el tiempo, y; e) todas las crisis de la historia son, de una u otra forma, crisis politicas ya que se originan en las principales esferas del poder politico vinculante. Si la hipótesis del COVID-19 como factor generador de un nuevo orden mundial es válida debe generar entonces una crisis histórica en estos términos.
} 
Escenarios prospectivos de un nuevo orden internacional que se vislumbra luego de la pandemia covid-19

\section{Escenarios prospectivos de un nuevo orden internacional que se vislumbra luego de la pandemia COVID-19}

La noción de escenarios prospectivos alude al decir de Baena Paz (2004), a la metodología y estudio transdisciplinario del futuro. En sintonía con lo planteado por Rivera Porto conjuntamente postula que: "(...) ayuda a medir las consecuencias, crear imágenes posibles y evaluar estas alternativas para encontrar oportunidades, brechas 0 incluso anti futuros que prevenir" (2004, p. 14). Se trata sin duda de una herramienta racional en construcción que intenta proponer respuestas anticipadas a los escenarios venideros sin por ello caer en la adivinación, la predicción profética propia de la metafísica religiosa o de la futurología de la ciencia ficción.

Aclarado esto, conviene precisar que todo intento fructifero por vislumbrar los posibles escenarios internacionales post-coronavirus imponen un conjunto amplio de preguntas como: ¿cuáles serán las características de los "nuevos" sistemas políticos y económicos? ¿estamos ante el fin de las economías de mercado y, por tanto, al retorno del esquema de planificación centralizada? ¿se aproxima una solución intermedia al problema de la escasez de recursos al modo de los estados de bienestar como garantía de un ingreso básico para la subsistencia general por encima del umbral de pobreza? ¿en el nuevo orden se experimentará el fin de las democracias liberales al estilo occidental? ¿habrá una propagación universal de estados autoritarios? ¿Qué rol van a desempeñar los nacionalismos y regionalismos en el mundo globalizado? ¿Cómo afectara a la persona humana la propagación a todos los ámbitos de la vida social de la inteligencia artificial? ¿Cuáles serán las nuevas modalidades de trabajo y educación?

De igual modo, en todos los escenarios imaginables parece que la humanidad va experimentar un conjunto de transformaciones biológicas y ontológicas que, según (Harari, 2015), serán propiciadas por la utilización general de ingeniería genética, nano-robótica e inteligencia artificial para ampliar de formas inimaginables las capacidades, habilidades y destrezas de las personas -en lo cognitivo, afectivo y procedimental- dando lugar a la emergencia de una especie distinta al homo sapiens que el historiador hebreo define desde ya como Entes. La impronta de estos entes, revolucionará a toda la civilización quizá propiciando un salto cuántico a una fase cualitativamente superior de nuestra historia 0 , tal vez, debido a un inusitado proceso de instrumentalización de la condición humana con consecuencias devastadoras para la vida en el planeta.

A partir de estas consideraciones y de las interrogantes formuladas, se procede a describir en líneas generales tres escenarios posibles a saber: 1) escenario de cambios parciales; 2) escenario de cambios sustanciales, y; 3 escenarios de transformación radical del orden mundial. Cada uno de estos escenarios pudiera estar gestándose desde ya en la transición que esta experimentado la gran familia de las naciones humanas y, su consolidación definitiva, se dará en la décadas venideras como resultado de la conjugación de fuerzas internacionales articuladas a distintos actores y factores de poder, que se mueven en todo momento en defensa de sus intereses particulares en el marco de un proceso estructuralsistémico que bien podría explicarse desde los algoritmos de la teoría de juegos o desde la teoría neorrealista. 


\section{Escenario de cambios parciales}

Por lo que representa este escenario es seguramente el más probable a desarrollarse en los tiempos venideros, mucha más cuando los actores de poder: estatales, económicos y corporativos, entre otros, que se benefician de las relaciones propias del OMV, como es natural harán todo los posible por no perder su hegemonía local-nacional-global y sus privilegios en una transición a un nuevo orden mundial radicalmente distinto en el cual pueden subvertirse las relaciones, los roles o los status estructurados hasta el momento.

De modo que, si bien es cierto la pandemia COVID-19 ha causado y sigue causando estragos en todas las dimensiones de las realidades nacionales y al mismo tiempo internacionales, su fuerza destructora no es suficiente para impulsar transformaciones estructurales en los sistemas políticos y económicos, por lo que solo se darán algunos cambios parciales que serán distintos de un país a otro, de acuerdo a sus necesidades y capacidades. En efecto, estos pequeños cambios o reformas serán suficientes para paliar la crisis y retornar paulatinamente a la normalidad perdida.

En este escenario el presente histórico sigue su curso desarrollando sus tendencias actuales y agudizando las contradicciones de los grandes paradigmas dominantes hasta que, en otra coyuntura que no se puede anunciar con exactitud, cercana o lejana, se alcancen las condiciones suficientes y necesarias para arribar a un OM diferente; circunstancia que lógicamente sucederá en algún momento e implicará un reacomodo de los estados nacionales en torno a nuevas ideas, dinámicas de intercambio y procedimientos, entre otros aspectos.

En lo fundamental, en un escenario así -de continuidad estructural- sistémica del OMVlas preguntas planteadas anteriormente no tienen mayor sentido, toda vez que, en lo esencial, el mundo seguirá regido por los mismos modelos, consensos, discursos y conceptos. No obstante, no se puede descartar que existe la posibilidad efectiva de que la transición a un nuevo orden mundial haya comenzado anteriormente y que, la pandemia COVID-19, más que la causa primaria de los cambios venideros sea la excusa para finiquitar un proceso que viene desarrollándose de forma subterránea tal como lo viene argumentando los trabajos de (Harari, $2014 ; 2015 ; 2018$ ) que indican, no solo el fin de OMV, sino la superación de la especie Homo sapiens por una entidad hibrida bio-robótica, que preludia a otra civilización en muchos sentidos post-humana.

\section{Escenario de cambios sustanciales}

Desde nuestra particular visión prospectiva, en un escenario de cambios sustanciales los viejos modelos de democracia liberal, economía de mercado o economías planificadas -los cuales son modales puros que sirven de base a otros modelos- experimentaran una serie de transformaciones que, por un lado, podrían desembocar dialécticamente en una transformación radical del orden mundial, aunque no se vislumbren alternativas solidas ${ }^{5}$ en los desarrollos

\footnotetext{
${ }^{5}$ En las últimas décadas han surgido algunos planteamientos que intentan superar a su modo los linderos impuestos por la dicotomía democracia liberal vs socialismo marxista, entre los que destacan por su impacto o coherencia argumentativa: La tercera vía de (Giddens, 1999) que se propuso ser la renovación de la democracia social, aunque en la práctica se adaptó muy bien a políticas neoliberales en el gobierno de Tony Blair en Inglaterra (1997-2007). También el trabajo de (Crouch, 2004) aporta luces sobre la postdemocracia, en tanto, concepto que ayuda a identificar aquellas situaciones de tensión que surgen en casi todas las naciones del occidente avanzado por el choque entre los intereses de las elites de poder y las grandes mayorias que ven frustradas sus aspiraciones, por autoridades y organizaciones políticas que no los representan. En ambos casos, se aboga por la necesidad de formular un nuevo pensamiento político y económico, en esencia y existencia distinto a todo lo conocido hasta ahora.
} 
Escenarios prospectivos de un nuevo orden internacional que se vislumbra luego de la pandemia covid-19

teóricos contemporáneos al respecto; por el otro, en una transformación profunda de los mismos que buscaría responder a las problemáticas y necesidades no resultas de la humanidad 0 , por lo menos, de la ciudadanía de los países desarrollados que tiene capacidad de respuesta y movilización ante algunos sistemas políticos y, simultáneamente, a las nuevas condiciones de convivencia post-coronavirus. Con todo, a pesar del agotamiento manifiesto de estos modelos sociopolíticos y económicos, su esencia es flexible y han demostrado capacidad adaptativa a las cambiantes circunstancias.

En una concepción dialéctica de la historia que no ve los procesos de forma lineal o solamente evolutiva, los escenarios que se plantean no son bloques aislados y estáticos lo que signifique que no sería descabellado suponer que una transición global que inicia a un escenario de cambios parciales, podría evolucionar bajo el dominio de ciertas fuerzas o circunstancias dispares a un escenario de cambios sustanciales para, finalmente, trascender a una transformación radical del orden mundial o, por el contrario, retornar al punto de inicio. Así de compleja es la historia humana. En cualquier caso, en este escenario intermedio se conjugan en igualdad de condiciones las fuerzas del cambio con las fuerzas neoconservadoras de la política, la cultura y la tradición.

\section{Escenario de transformación radical del orden mundial}

En este escenario la humanidad se adentraría a un mundo incierto en el cual todas las certezas simbólicas y materiales construidas o impuestas a las distintas sociedades como garantía de gobernanza y gobernabilidad quedarían desfazadas y tendrían, por lo tanto, que ser sustituidas a un ritmo variable pero perentorio, por nuevos modelos, instituciones, rituales y prácticas en el marco de otra arquitectónica internacional, que no sabemos bajo que referentes epistemológicos, jurídicos o contractuales seria configurada. Se podría tratar entonces del inicio de otra etapa para toda la civilización, así como sucedió en su momento con el renacimiento, el oscurantismo o la ilustración, con nuevos repartos de los espacios de poder y sus consecuentes reacomodos entre actores nacionales, regionales y mundiales.

Al decir de Goedder (2020), los primeros cambios radicales en los dominios de la política generados por la pandemia tienen que ver con un retorno a formas autoritarias del ejercicio del poder que erosiona por igual a la democracia y al estado de derecho. Este retorno o refuerzo de la autocracia se aprovecha, en oriente y occidente, del miedo de las personas ante la crisis y las muertes masivas producidas por el agente viral, pero ¿son estas prácticas pasajeras o terminaran normalizándose en los imaginarios colectivos del poder? ¿habrá una propagación universal de estados autoritarios? Para el momento en se escriben estas líneas nada está claro, mucho menos en las sociedades del sur global donde en mayor o menor medida las democracias existentes son frágiles o de muy poca calidad, tal como sostiene (Morales Castro, 2018).

Si finiquitada la segunda guerra mundial el principal debate entre los estados nacionales triunfantes del momento, era construir una hegemonía mundial con base precisamente a las victorias obtenidas en la conflagración, ahora en la segunda década del siglo XXI, todo apunta que el debate será entorno a los modelos que gobernaran el mundo venidero, en tanto, representación de los intereses no solo de estados nacionales sino, igualmente, siguiendo a (Huntington, 1997), de ciertas identidades culturales y religiosas en permanente disputa como lo evidencia el caso del islam y occidente, del estado teocrático vs el estado laico 
y democrático, de ahí que reiteramos la pregunta ¿cuáles serán las características de los "nuevos" sistemas políticos y económicos?

Desde ya se pudieran imaginar varias alternativas a este pregunta pero sin arriesgarnos a proponer una contestación definitiva al tema, cosa que es hasta ahora técnicamente imposible, porque los modelos existentes hasta el presente han fracasado a su modo y también porque más allá de las diferentes mixturas y combinaciones entre los modelos puros, tales como: el estado de bienestar, la democracia social de la tercera vía, el socialismo liberal de Bobbio o la economía social de mercado de los alemanes, no hay un nuevo pensamiento para regir los destinos de la humanidad, lo que significa que seguimos anclados a modelos que provienen, a su vez, de sistemas filosóficos del siglo XVIII y XIX, entre los que resaltan: el pensamiento liberal ilustrado, el marxismo, el evolucionismo y el positivismo.

A pesar de que el estado nacional o multinacional ha sido hasta el momento la máxima expresión del poder político vinculante, no significa que en un futuro próximo esta forma de organización de paso a un gobierno mundial, como propone Resnick (2007), o aun tipo de gobierno horizontal de las sociedades humanas de tipo post-estatal y federativo como han teorizado los anarquistas. En cualquiera de estos contextos, la transición vendría a desarticular los cimientos de la globalización y hasta tanto no se defina una nueva arquitectónica internacional, se experimentará un retorno a los nacionalismos y a políticas proteccionistas ganadas a propiciar el desarrollo endógeno, desde las localidades.

Quizá en un contexto así los sistemas económicos se moverán de forma pendular desde los parámetros de las economías de mercado, hasta ciertas nociones tipas de la planificación centralizada, útil cuando se trata de construir bienestar social colectivo y capacidades productivas en regiones y localidades en las cuales las fuerzas invisibles del mercado y las políticas modernizadoras no han sido suficientes para hacerlas despegar. No obstante, por lo contradictorio de un sistema así, supones que su vigencia será únicamente transitoria hasta tanto surja y se consolide un nuevo modelo alternativo en la escena de un NOM.

$\mathrm{Si}$ algo queda claro en la pandemia es que no son las iniciativas privadas de las pequeñas, medianas o grandes empresas, las que aportan soluciones a la crisis que llevo al colapso de los sistemas sanitarios incluso en los países desarrollados, lo que pone en cuestión las tesis del estado mínimo formulada por el pensamiento neoliberal como condición para el desarrollo. De hecho, en países como EUA, diversos intelectuales según Izquierdo (2020) cuestionan las limitaciones inherentes a la privatización generalizada del sector salud porque limita significativamente la capacidad estratégica de respuesta del Estado en momentos de crisis. Esta compleja realidad reposiciona al Estado como principal garante del bienestar colectivo y como el único instrumento del poder social responsable de garantizar un ingreso mínimo de subsistencia general en contextos catastróficos donde se detienen las economías nacionales.

En una trasformación radical de OMV la inteligencia artificial será un agente fundamental que afectará, para bien o para mal, la vida de las personas al tiempo que traería consigo cambios inusitados en el trabajo y la educación. Como sostienen Brito et al (2019):

(...) la IA ha significado y podría significar un gran aporte para mejorar la calidad de vida de las personas en ámbitos tan diversos como: la informática, la salud, la seguridad bancaria, las telecomunicaciones, los softwares de supervisión industrial y el entretenimiento. Sin embargo, el desarrollo vertiginoso de la IA podría desembocar 
Escenarios prospectivos de un nuevo orden internacional que se vislumbra luego de la pandemia covid-19

en el surgimiento de organismos cibernéticos inteligentes, dotados de autonomía y voluntad capaces de entrar en conflicto con la condición humana en la medida en que su actuación perjudique los postulados bioéticos básicos (p. 278).

Cada día más, las obras de ciencia ficción de antaño son superadas por una realidad en la cual dispositivos tecnológicos en la forma de hardware y software de inteligencia artificial (Al), vienen a complementar a la inteligencia humana en el trabajo, la educación y la recreación, por lo que no sería osado suponer que en un NOM la Al pudiera terminar por controlar, con un mínima de supervisión humana, los grandes procesos especializados, económicos y políticos, al facilitar la toma de decisiones racionales en un clima libre del influjo de intereses subjetivos y emocionalidad o; como sostiene (Harari, 2014; 2015), la Al con su capacidad de auto-modelado terminaría por fusionarse con la persona humana revolucionando todas las dimensiones de su ser y hacer lo que implica un salto cuántico de "Animales a Dioses".

\section{Consideraciones finales}

El proceso de declive y erosión de los principales paradigmas: políticos, económicos e ideológicos, de la modernidad, que organizan a las comunidades humanas, gestionan sus conflictos, sirven de modelo interpretativo para dotar de sentido a las cambiantes realidades $y$, al mismo tiempo, administran recursos siempre escasos, no es algo reciente. De hecho, la filosofía postmoderna ya denuncia este fenómeno desde la década de los setentas del siglo XX bajo la premisa del fin de los grandes relatos, en palabras de Lyotard los metarrelatos:

...son aquellos que han marcado la modernidad: emancipación progresiva de la razón y de la libertad, emancipación progresiva o catastrófica del trabajo (fuente de valor alienado del capitalismo), enriquecimiento de toda la humanidad a través del progreso de la tecnociencia capitalista, e incluso, si se cuenta al cristianismo dentro de la modernidad (opuesto, por lo tanto, al clasicismo antiguo), salvación de las creaturas por medio de la conversión de las almas vía el relato crístico del amor mártir. La filosofía de Hegel totaliza todos estos relatos y, en este sentido, concentra en sí misma la modernidad especulativa (Lyotard, 1987, p. 55).

A pesar de este posicionamiento crítico los metarrelatos modernos como el socialismo y el capitalismo -en su vinculación con de la democracia liberal- han seguido fungiendo como la única alternativa cuando se trata de mantener las estructuras del OMV, lo que pone en evidencia la falta de creatividad para construir mancomunadamente un nuevo pensamiento político y económico para la puesta en marcha de modelos más acordes a las nuevas realidades presentes y porvenir. Si a esto se le suma los grandes problemas no resueltos del mundo actual como el calentamiento global, la pobreza extrema que se vive en los países del sur global y le inequidad en términos de relaciones de poder que subordinan a buena parte de los estados del mundo, entonces la crisis del orden mundial antecede por mucho a la impronta de la pandemia COVID-19.

De cualquier modo, hasta cierto punto es válido afirmar la hipótesis de que la COVID19 significa un punto de inflexión en la arquitectónica del sistema internacional propio del OMV, que traerá consigo la implementación progresiva de reformas o cambios sustanciales, según el caso, que marcaran un antes y un después en las relaciones entre actores y factores de poder 
a nivel mundial, así como en los mundos de vida de las personas comunes. De ahí que, el ejercicio de hermenéutica dialógica y análisis prospectivo nos permitió formular para el debate y la discusión sosegada tres escenarios que buscan presagiar las realidades futuras que envolverán a la humanidad en su conjunto.

\section{Referencias Bibliográficas}

Arbeláez-Campillo, Diego Felipe; Andreyevna Dudareva, Marianna y Rojas-Bahamón, Magda Julissa. (2019). Las pandemias como factor perturbador del orden geopolítico en el mundo globalizado. Cuestiones Políticas. 36 (63). Venezuela. (pp. 134-150).

Baena Paz, Guillermina. (2004). Prospectiva política Guía para su comprensión y práctica. Universidad Nacional Autónoma de México. México.

Barría, Cecilia. (2020). Coronavirus: "Estamos frente a una crisis generalizada del capitalismo democrático mundial y del no democrático, como el de China". BBC news/mundo. Extraído de: https://www.bbc.com/mundo/noticias-52055657

Brito Paredes, Patricio; Villavicencio Aguilar, Carmita y Sánchez Saca, Pamela. (2019). Reflexiones sobre posibles conflictos entre la inteligencia artificial y el futuro de la sociedad. Revista de la Universidad del Zulia. (23), Venezuela (pp. 260-280).

Caballero, Manuel. (2007). Las crisis de la Venezuela contemporánea (1903-1992). Alfadil Ediciones. Venezuela.

Calvano Cabezas, Leonardo. (2019). Apuntes sobre los desafíos que entraña el nuevo contrato social para Colombia en tiempos del postconflicto. Cuestiones Políticas. 36 (63), Venezuela (pp. 14-29).

Crouch, Colin. (2004). Posdemocracia. Taurus. España.

Fukuyama, Francis. (2015) ¿El fin de la historia y otros ensayos? Y otros ensayos. Alianza editorial. España.

Gadamer, Hans-Georg. (1993). Verdad y método Fundamentos de una hermenéutica filosófica. Quinta edición. Ediciones Sígueme. España.

Giddens, Anthony. (1999). La tercera vía La renovación de la socialdemocracia. Taurus. España.

Goedder, Carlos. (2020). El rechazo libertario al tiranovirus El manejo del Coronavirus consolida el totalitarismo y el miedo a la libertad. CEDICE libertad. Extraído de: http://libreriacedice.org.ve/wp-content/uploads/2020/04/cedice tiranovirus.pdf

Harari, Yuval Noah. (2014). De animales a dioses Breve historia de la humanidad. Tercera edición. Debate. España.

Harari, Yuval Noah. (2015). Homo Deus Breve historia del mañana. Editorial digital Titivillus. España.

Harari, Yuval Noah. (2018). 21 lecciones para el siglo XXI. Debate. España.

Huntington, Samuel P. (1997). El choque de civilizaciones: y la reconfiguración del orden mundial. Ediciones Paidós Ibérica. España.

Izquierdo, José M. (2020). El insoluble problema de la salud en EEUU. El Nuevo Herald. Extraído de: https://www.elnuevoherald.com/opinion-es/cartas/article180019876.html

Kasper, Wolfgang. (2015). Libertad Económica y Desarrollo. University of New South Wales. Australia. 
Lichfield, Gideon. (2020). Aceptémoslo, el estilo de vida que conocíamos no va a volver nunca.

MIT Technology Review. Extraído de:

https://www.technologyreview.es/s/12034/aceptemoslo-el-estilo-de-vida-queconociamos-no-va-volver-nunca

Lissardy, Gerardo. (2020). Coronavirus: los 2 grandes escenarios mundiales que plantean algunos expertos para después de la pandemia. BBC news/mundo. Extraído de: https://www.bbc.com/mundo/noticias-internacional-52526090

Lyotard, Jean-François. (1987). La condición postmoderna Informe sobre el saber. Teorema. Argentina.

Martz Fernández, Francys. (2017). Transición política: un mapeo teórico en medio de la dispersión bibliográfica. Cuestiones Políticas. 33 (59), Venezuela (pp. 58-84).

Morales Castro, Yolanda Rosa. (2018). Familia y socialización política en Colombia. Primera edición. Fondo editorial de la UNERBM. Venezuela.

Morales Castro, Yolanda Rosa; Villasmil Espinoza, Jorge Jesús y Martínez Pure, Rubén Darío. (2019). Democracia a la palestra: ¿Gobierno del pueblo o degeneración del poder? Revista de Ciencias Sociales. XXV, (Especial), Venezuela (pp. 236-252).

Naciones Unidas. (1948). Declaración Universal de los Derechos Humanos. Extraído de: https://www.un.org/es/universal-declaration-human-rights/

Parra Contreras, Reyber. (2020). Una perspectiva del mundo que se nos avecina. Revista de la Universidad del Zulia. 11 (29), Venezuela (pp. 3-5)

Popper, Karl. (1945). La sociedad abierta y sus enemigos. Editorial digital Titivillus. España. Resnick, Philip. (2007). La democracia del siglo XXI. Anthropos. España.

Ritzer, George. Teoría sociológica clásica. (2005). Tercera edición. Mc Graw Hill. España.

The New York Time. (2020). Coronavirus in the U.S.: Latest Map and Case Count. The New York

Time. Extraído de: https://www.nytimes.com/interactive/2020/us/coronavirus-uscases.html

Toro Hardy, Alfredo. (2007). Hegemonía e imperio. Villegas editorial. Colombia.

Vergara Henríquez, Fernando J. (2011). Gadamer y la hermenéutica de la comprensión dialógica: historia y lenguaje. Revista de Filosofía. 28 (69), Venezuela (pp. 74-93).

Villasmil Espinoza, Jorge Jesús y Chirinos Portillo, Loiralith. (2016). Reflexiones sobre Derechos Humanos, multiculturalidad y diálogo intercultural. Opción: Revista de Ciencias Humanas y Sociales. 32 (79), Venezuela (pp. 197-216). 